\title{
The Application of Fuzzy Level Evaluation in Occupational Ability Evaluation for Higher Vocational Students
}

\author{
Tan Weiqi \\ Anqing Vocational and Technical College, Anqing, 243001 China \\ E-mail: twq@aqvtc.cn
}

Keywords: occupational ability; factor weight; fuzzy level evaluation

\begin{abstract}
Occupational ability consists of three levels according to the theory of system composition: special professional skills, industry generic skills and core skills. Analytic hierarchy process is used to establish the hierarchical structure model, construct the comparison matrix, calculate the weights of the factors and test the consistency. The factors influencing the fuzzy judgment matrix can be determined by using fuzzy evaluation method. Scores of the affecting factors can be got reversely, which provides the basis for the judgment of the students' occupational ability levels and the affecting factors. Using fuzzy level evaluation to evaluate occupational ability of higher vocational students provides a new method for occupational ability evaluation.
\end{abstract}

\section{Introduction}

Nowadays, vocational education in China has been changed from expanding quantity to improving quality and it has formed into a curriculum system which takes occupational ability as the core. In this way, the quality of graduates under vocational education has improved more than before ${ }^{[1][2]}$. Generally speaking, vocational college students will be granted graduation and skill certificate after finishing vocational education. However, whether the students' occupational abilities have formed or not and what type of job can be satisfied are still hard to determined. Thus, it gets very necessary and urgent to evaluate graduates" occupational abilities. Because of many related factors in occupational ability, researchers in China lack the corresponding exploration and research on factors organic integration and working out a convincing evaluation result. This article combines fuzzy evaluation method with level evaluation method and applies them to evaluating occupational ability so as to provide some beneficial explorations for it.

\section{The composition of occupational ability}

On the occupational ability, different subjects have different understanding. Psychology defines occupational ability as 'the Individual psychological characteristics which have direct influence on the efficiency of occupational activity and keep it go on successfully; CBE

(Competency-Based Education) holds the point that occupational ability is the knowledge, skills, attitudes and experience required to complete specific occupational activities. Structuralism regards occupational ability as "comprehensive occupational ability" which includes physical and mental quality, professional ethics, entrepreneurial spirit, skills and all factors required by specific occupational activities. Process school thinks "the formation and development of occupational ability must get involved in specific occupational activities or simulation career situation. With the transfer by generalization of existing knowledge and skills, related general ability get developed and integrated specially in order to form a stable comprehensive ability." Because of different understandings on occupational ability, it varies in its composition. In terms of component, occupational ability includes three parts: professional ability, method ability and society ability; In terms of level evaluation for occupational ability, it includes three levels: specific occupational skills, industry general skills and core skills. Combining the points above, we apply the level concept of occupational ability to factor compositions and we have occupational ability structure map. [3] 


\section{Basic process for fuzzy level evaluation method Recognition of level weight}

Establishing the level structure model-From all kinds of understanding of occupational ability, we divide related several factors into four level from top to bottom according to their own attributes. Factors in the same level belong to or have influence on higher level factors. At the same time, they control or get affected by the next level factors. The top level is defined as A (Occupational Ability) ; the second level has two parts: general method and ability $\mathrm{B}_{11}$ (General method \& ability) and comprehensive occupational ability level $\mathrm{B}_{12}$ (Comprehensive occupational ability) ; the third level has 6 factor indexes: $\mathrm{C}_{11}$ (Professional ability)、 $\mathrm{C}_{12}$ (General occupational ability)、 $\mathrm{C}_{13}$ (Social ability)、 $\mathrm{C}_{21}$ (Professional ability)、 $\mathrm{C}_{22}$ (Method \& Ability)、 $\mathrm{C}_{23}$ (Social ability); the fourth level has 22 factors indexes: $\mathrm{D}_{11}$ (Occupational Knowledge) 、 $\mathrm{D}_{12}$ (Occupational Skills) 、 $\mathrm{D}_{21}$ (Occupational learning method)、 $\mathrm{D}_{22}$ (Occupational woring method)、 $\mathrm{D}_{31}$ (Cooperative ability)、 $\mathrm{D}_{32}$ (Communicative ability)、 $\mathrm{D}_{33}$ (Environment perception consciousness)、 $\mathrm{D}_{34}$ (Work ethic)、 $\mathrm{D}_{41}$ (Comprehensive ability of new tech)、 $\mathrm{D}_{42}$ (Occupational adjusting ability)、 $\mathrm{D}_{43}$ (Quality economic consciousness)、 $\mathrm{D}_{44}$ (Technical renovation ability)、 $\mathrm{D}_{45}$ (Market operation ability)、 $\mathrm{D}_{51}$ (Analyzing \& integrating)、 $\mathrm{D}_{52}$ (Innovation ability)、 $\mathrm{D}_{53}$ (Information using ability) 、 $\mathrm{D}_{54}$ (Decision-making ability)、 $\mathrm{D}_{61}$ (Organize and coordinate ability)、 $\mathrm{D}_{62}$ (Psychological endurancing capacity)、 $\mathrm{D}_{63}$ (Social responsibility)、 $\mathrm{D}_{64}$ (Positive working)、 $\mathrm{D}_{65}$ (Self cognitive ability),

Structuring paired comparison matrix: from the second level in level structure model, factors in the same level which belong to (or influence) the each higher factor are used to build comparison matrix by paired comparison method as figure 1 . We defined the result as: $B 、 C_{1} 、 C_{2} 、 D_{1} 、 D_{2}$ 、 $\mathrm{D}_{3} 、 \mathrm{D}_{4} 、 \mathrm{D}_{5}$ and $\mathrm{D}_{6}$.

$$
A=\left[\begin{array}{llll}
\frac{w_{1}}{w_{1}} & \frac{w_{1}}{w_{2}} & \cdots & \frac{w_{1}}{w_{n}} \\
\frac{w_{2}}{w_{1}} & \frac{w_{2}}{w_{2}} & \cdots & \frac{w_{2}}{w_{n}} \\
\cdots & \ldots & \cdots & \ldots \\
\frac{w_{n}}{w_{1}} & \frac{w_{n}}{w_{2}} & \cdots & \frac{w_{n}}{w_{n}}
\end{array}\right]
$$

Fig. 1: Structure of paired comparison matrix

In order to report people's common cognition and collect expertise, we invited experts to take the survey by using Delphi method. According to the conclusion from article ${ }^{[4]}$, the more people involved, the better the result will be. Take time and economy aspects into consideration, this time 12 vocational education experts were selected. We divided the hierarchy into 3 levels: important, more important and the most important by using odd numbers (such as 9, 7, 5, 3, 1) or its reciprocal as quantitative criteria. As for the hierarchy between two higher levels, we express the part that is difficult to judge as even numbers $(8,6,4,2$,). We evaluate the relative importance comparing the factors in same level to the factor in a higher level in order to build comparison matrix. After four turns of feedbacks, we collected opinions with relative concentration. We arranged consistency check for the data collected from each expert in the last turn. According to the theory in the article ${ }^{[5]}$, if the data passes the check, we then merge the judgment matrix.

We firstly calculate the largest eigenvalue $\sigma$, since the largest eigenvalue of complete consistent judgment matrix is $\mathrm{n}, \lambda=\sigma-\mathrm{n}$ is the deviation of judgment matrix between experts' and check's result. After that, we calculate $\lambda=\frac{\frac{1}{\lambda_{i}}}{\sum_{i=1}^{12} \frac{1}{\lambda_{i}}}$, and use the normalized $\lambda$ as weighting coefficient of the corresponding expert judgment matrix. We then build final judgment matrix: $R=A_{1_{1}}^{\lambda_{1}} \oplus A_{2}^{\lambda_{2}} \oplus \cdots \oplus A_{12}^{\lambda_{12}}$, $\mathrm{R}$ is the Hadamard combination of expert judgment matrix. 
Hadamard combination takes experts' opinions into consideration sufficiently and minimizes the deviation of judgment matrix between experts' and check's result. The final matrixes are:

$$
\begin{aligned}
& \mathrm{B}=\left[\begin{array}{cc}
1 & 0.309 \\
3.235 & 1
\end{array}\right] ; \quad \mathrm{C}_{1}=\left[\begin{array}{ccc}
1 & 2.333 & 0.412 \\
0.427 & 1 & 0.177 \\
2.429 & 5.6667 & 1
\end{array}\right] ; \quad \mathrm{C}_{2}=\left[\begin{array}{ccc}
1 & 1.436 & 3.160 \\
0.696 & 1 & 2.200 \\
0.317 & 0.455 & 1
\end{array}\right] \quad \mathrm{D}_{1}=\left[\begin{array}{cc}
1 & 0.787 \\
1.270 & 1
\end{array}\right] ; \quad \mathrm{D}_{2}=\left[\begin{array}{cc}
1 & 0.579 \\
1.727 & 1
\end{array}\right] \text {; } \\
& D_{3}=\left[\begin{array}{cccc}
1 & 1.417 & 0.486 & 0.378 \\
0.706 & 1 & 0.343 & 0.267 \\
2.059 & 2.917 & 1 & 0.778 \\
2.647 & 3.750 & 1.286 & 1
\end{array}\right] \\
& \mathrm{D}_{4}=\left[\begin{array}{ccccc}
1 & 0.914 & 1.28 & 0.377 & 0.492 \\
1.094 & 1 & 1.4 & 0.412 & 0.536 \\
0.781 & 0.714 & 1 & 0.294 & 0.385 \\
2.656 & 2.427 & 3.4 & 1 & 1.308 \\
2.031 & 1.857 & 2.6 & 0.765 & 1
\end{array}\right] \\
& D_{6}=\left[\begin{array}{ccccc}
1 & 5.235 & 1.328 & 0.937 & 2.543 \\
0.191 & 1 & 0.254 & 0.179 & 0.486 \\
0.753 & 3.941 & 1 & 0.705 & 1.914 \\
1.067 & 5.588 & 1.418 & 1 & 2.714 \\
0.393 & 2.059 & 0.522 & 0.386 & 1
\end{array}\right] . \\
& \mathrm{D}_{5}=\left[\begin{array}{cccc}
1 & 0.6 & 0.771 & 1.5 \\
1.667 & 1 & 1.286 & 2.5 \\
1.296 & 0.778 & 1 & 1.944 \\
0.667 & 0.4 & 0.514 & 1
\end{array}\right]
\end{aligned}
$$

\section{Calculating weight vector and implementing consistency check}

We calculate the largest eigenvalue by using power method and get eigenvalue from matrix; after normalizing the eigenvalue, we will have weight of factors in different levels. We take $D_{6}$ as an example to calculate. First of all, multiply each column in $\mathrm{D}_{6}$ and then the results are $(16.5670$ $0.00424 .005622 .95690 .15580)^{\mathrm{T}}$. Extracting fifth power of each factor, the results are $(1.7533$ $0.33491 .31991 .87150 .6895)^{\mathrm{T}}$. With normal processing, turns to be characteristic vectors $(0.2937$ $0.05610 .22110 .31350 .1155)^{\mathrm{T}}$ which are the weights of factors in level $\mathrm{D}_{6}$. According to the formula $\lambda_{\max }=\frac{1}{n} \sum \frac{(A \bar{W})_{i}}{W_{i}}, \lambda_{\max }=5.0005$; by $C I=\frac{\lambda_{\max }-n}{n-1}$, we have CI=1.2500e-004; CR=CI/RI=

\begin{tabular}{|c|c|c|c|c|}
\hline & Characteristic vector. & Eigenvalue & $\mathrm{CI}$ & $\mathrm{CR}$ \\
\hline $\mathrm{B}$ & $(0.23610 .7639)^{\mathrm{T}}$ & 2.0001 & $1.0000 \mathrm{e}-004$ & \\
\hline $\mathrm{C} 1$ & $(0.25930 .11110 .6296)^{\mathrm{T}}$ & 3.004 & 0.001 & 0.0017 \\
\hline $\mathrm{C} 2$ & $(0.49690 .34590 .1572)^{\mathrm{T}}$ & 3.0002 & $1.0000 \mathrm{e}-004$ & $1.7241 \mathrm{e}-004$ \\
\hline D1 & $(0.44050 .5595)^{\mathrm{T}}$ & 2.0 & 0 & \\
\hline $\mathrm{D} 2$ & $(0.36670 .6333)^{\mathrm{T}}$ & 2.0002 & $1.0000 \mathrm{e}-004$ & \\
\hline D3 & $(0.15600 .11010 .32110 .4128)^{\mathrm{T}}$ & 4.0005 & $1.6667 \mathrm{e}-004$ & $1.8519 \mathrm{e}-004$ \\
\hline D4 & $\begin{array}{llll}0.1322 & 0.1446 & 0.1033 & 0.3512\end{array}$ & 5.0006 & $1.5000 \mathrm{e}-004$ & $1.3393 \mathrm{e}-004$ \\
\hline D5 & $(0.21600 .36000 .28000 .1440)^{\top}$ & 4.0013 & $4.3333 \mathrm{e}-004$ & $4.8148 \mathrm{e}-004$ \\
\hline D6 & $\left(\begin{array}{llll}0.2937 & 0.0561 & 0.2211 & 0 .\end{array}\right.$ & 5.0005 & $1.2500 \mathrm{e}-004$ & $11161 \mathrm{e}-004$ \\
\hline
\end{tabular}
1.1161e-004, CI and CR both less than 0.1 , C passes consistency check ${ }^{[6]}$. We calculate each judgment matrix

by following steps mentioned above and have final results shown in table 1 .

Table 1 Characteristic vector, eigenvalue, CI and CR of level B, C and D

A. Fuzzy evaluation

- Determine the fuzzy evaluation set

We define the degree of occupational ability set as $\mathrm{V}=\mathrm{f}\left(\mathrm{V}_{1}, \mathrm{~V}_{2}, \mathrm{~V}_{3}, \mathrm{~V}_{4}, \mathrm{~V}_{5}\right)=\{$ Advanced strong ability, Strong ability, Common ability, Less low ability, Low ability \}. With expert consultation method, $90-100$ is advanced strong ability, 70-90 is strong, 50-70 is common, 30-50 is less low and score less than 30 is low ability. Afterwards, quantize the evaluation set by 1-point-

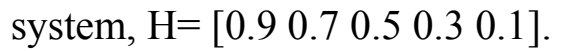

- Determine the fuzzy evaluation matrix

We then asked vocational education experts to score each four-level index depending on students' grades and performances particularly. The results will be divided into different sets according to the standard mentioned above. Finally, we will get fuzzy evaluation 
$R_{4}=\left[\begin{array}{cccc}r_{411} & r_{412} & \cdots & r_{415} \\ r_{421} & r_{422} & \cdots & r_{425} \\ \cdots & \cdots & \cdots & \cdots \\ r_{4 n 1} & r_{4 n 2} & \cdots & r_{4 n 5}\end{array}\right]$. Now 4 students are selected by random, take one of the students as an example, the fuzzy evaluation matrix is:

$D_{41}=\left[\begin{array}{ccccc}0.8 & 0.1 & 0.1 & 0 & 0 \\ 0.6 & 0.15 & 0.15 & 0.1 & 0\end{array}\right] ; D_{42}=\left[\begin{array}{ccccc}0.7 & 0.2 & 0.1 & 0.05 & 0.05 \\ 0.4 & 0.4 & 0.0 & 0 & 0.05\end{array}\right]$

$D_{44}=\left[\begin{array}{ccccc}0.1 & 0.5 & 0.1 & 0.2 & 0.1 \\ 0.8 & 0.1 & 0.1 & 0 & 0 \\ 0.9 & 0.1 & 0 & 0 & 0 \\ 0.1 & 0.6 & 0.15 & 0.1 & 0.05 \\ 0.3 & 0.4 & 0.2 & 0 & 0.1\end{array}\right] \quad D_{45}=\left[\begin{array}{ccccc}0.5 & 0.4 & 0 & 0.05 & 0.05 \\ 0.1 & 0.7 & 0.1 & 0.1 & 0 \\ 0.1 & 0.1 & 0.8 & 0 & 0 \\ 0.2 & 0.2 & 0.5 & 0.1 & 0\end{array}\right] ; \quad D_{46}=\left[\begin{array}{ccccc}0.9 & 0.05 & 0.05 & 0 & 0 \\ 0.5 & 0.4 & 0.05 & 0 & 0.05 \\ 0.4 & 0.3 & 0.2 & 0.05 & 0.05 \\ 0.3 & 0.3 & 0.3 & 0.05 & 0.05 \\ 0.2 & 0.55 & 0.1 & 0.1 & 0.05\end{array}\right]$

Firstly, calculate fuzzy evaluation matrix of level C:

$C_{11}=\left[\begin{array}{l}D_{41}^{T} * D_{1} \\ D_{42}^{T} * D_{2} \\ D_{43}^{T} * D_{3}\end{array}\right]=\left[\begin{array}{ccccc}0.6881 & 0.1280 & 0.1280 & 0.0560 & 0 \\ 0.51 & 0.3267 & 0.0367 & 0.0183 & 0.05 \\ 0.5339 & 0.2743 & 0.0959 & 0.0583 & 0.0376\end{array}\right]$

$C_{12}=\left[\begin{array}{l}D_{44}^{T} * D_{4} \\ D_{45}^{T} * D_{5} \\ D_{46}^{T} * D_{6}\end{array}\right]=\left[\begin{array}{lllll}0.3376 & 0.4091 & 0.1341 & 0.0616 & 0.0576 \\ 0.2008 & 0.3952 & 0.3320 & 0.0612 & 0.0108 \\ 0.4980 & 0.2610 & 0.1673 & 0.0383 & 0.0353\end{array}\right]$

Secondly, calculate the score of fuzzy evaluation of level C:

$S_{c}=\left[\begin{array}{l}C_{11} * H^{T} \\ C_{12} * H^{T}\end{array}\right]=\left[\begin{array}{llllll}0.7897 & 0.7165 & 0.7417 & 0.6815 & 0.6428 & 0.7296\end{array}\right]^{T}$ level B:

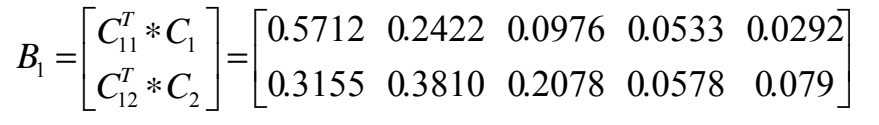

$\mathrm{B}$,

Thirdly, calculate fuzzy evaluation matrix of

$S_{b}=B_{1} * H^{T}=\left[\begin{array}{ll}0.7513 & 0.6757\end{array}\right]^{T} \quad$ Calculate fuzzy evaluation matrix of level A,

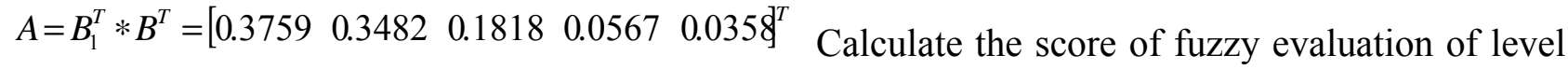
A,

$S_{a}=A * H^{T}=0.6935$.In this way, scores of level A, B and $\mathrm{C}$ of the other three samples can be calculated. The final result is shown as following table 2

\begin{tabular}{|c|c|c|c|c|c|c|c|}
\hline No. & Level A & Level B & Level C & & & & \\
\hline 1 & 0.6935 & {$\left[\begin{array}{ll}0.7513 & 0.6757\end{array}\right]^{\mathrm{T}}$} & $\begin{array}{l}0.7897 \\
0.7296]^{\mathrm{T}}\end{array}$ & 0.716 & 0.7417 & 0.6815 & 0.6428 \\
\hline 2 & 0.7245 & {$\left[\begin{array}{ll}0.7148 & 0.8757\end{array}\right]^{\mathrm{T}}$} & $\begin{array}{l}0.6452 \\
0.7895]^{\mathrm{T}}\end{array}$ & 0.716 & 0.5879 & 0.7843 & 0.7238 \\
\hline 3 & 0.7418 & {$\left[\begin{array}{ll}0.8116 & 0.8012\end{array}\right]^{\mathrm{T}}$} & $\begin{array}{l}{\left[\begin{array}{r}0.7521 \\
0.7412\end{array}\right]^{\mathrm{T}}} \\
0\end{array}$ & 0.771 & 0.8014 & 0.7424 & 0.8256 \\
\hline 4 & 0.7852 & {$\left[\begin{array}{ll}0.8014 & 0.7915\end{array}\right]^{\mathrm{T}}$} & $\begin{array}{l}{\left[\begin{array}{r}0.8326 \\
0.8127]^{\mathrm{T}}\end{array}\right.} \\
\end{array}$ & 0.764 & 0.6518 & 0.9317 & 0.7983 \\
\hline
\end{tabular}

Table 2. Sampling scores of students' fuzzy evaluation

Ranking scores in level A, the data is $(4,3,2,1)$, from which students can learn the relative position information for their occupational ability and employers can be informed of 
occupational ability information of each graduate; what's more, scores in level B have 2 parts: general occupational ability and comprehensive occupational ability, from which students can learn advantages in their occupational ability and employers can select employees by considering applicants' comprehensive occupational ability according to the actual demand; scores in level C have 6 parts, the maximum in each row indicates students performing the best in this special occupational ability, which provides job information for students and employers.

\section{Conclusion}

A. Fuzzy level evaluation method can analyze students' occupational ability in different levels, which provides a new method for occupational ability analysis.

B. Occupational ability evaluation provides feedback information for teaching process

Fuzzy level in occupational ability evaluation takes factors that have relative influence on occupational ability into comprehensive consideration. According to the theory of systematics and fuzzy level analysis method, the data which is of quality and quantity information can report students' performances in occupational ability. The work provides accurate feedbacks for teaching process, management, curriculum designing, and teaching activities between professors and students. By coming up with causes of success and failure, educational reformation will seek practical basis to keep on in the future.

C. Provide guidance for students' employment and recruitment

Every job has its corresponding requirement for occupational ability. The job needs a suitable individual with particular ability. With the feedback result from fuzzy level evaluation in occupational ability, students can choose the matching job according to their strengths in occupational ability; employers can also select well-matched applicants by job's requirements.

\section{Acknowledgment}

When it comes to the acknowledgment, I want to give many thanks to all that helped me. I want to give my heartfelt thanks to this study "The cooperative personnel training base about landscape plants between agriculture, science and education" (2012sjjd055). To sum up, thank you all for all your consideration!

\section{References}

[1] Shanghai education scientific research institute, Mikes institute, Annual report of personnel training quality in Chinese higher vocational education 2012 [N]. China Education Daily, $10 / 17 / 2012$. 5th edition

[2] Jia Jianfang, Component analysis of occupational ability in higher vocational education [J]. Guangdong technology normal university, 2010(2):117-121.

[3 ]Jia Jianfang, Guo Libing, Liu Shengping, Component analysis of occupational ability [J]. Wuxi commercial vocational and technical college journal, 2010.10(4):57-61.

[4] Liu Xinbao, Convexity of consistency in judgment matrix [J]. System engineering theory and practice,1997 (4) : 87-89.

[5] Liu Xinbao, Yang Shanlin, Hadamard convex combination of judgment matrix [J]. System engineering theory and practice,2000 (4) : 83-86.

[6] Ren Shanqiang etc., Mathematical model [M]. Chongqing University Press 2008-5, 3rd edition, $205 \sim 206$ 